\title{
Tıp ve Sağlık Bilimleri Kütüphaneciliğinde Ulusal ve Uluslararası Dernek Oluşumları
}

\author{
Formation of National and International Associations of \\ Medical and Health Sciences Libraries
}

\section{Güssün GÜNEŞ}

\begin{abstract}
Öz
Tıp kütüphaneleri tıbbî bilginin sınıflandırılması, saklanması ve kullanıma sunulması açısından önemli işlevler yüklenmiştir. Tıp kütüphanelerinin 1850 'den bu yana sürekli gelişme halinde oldukları gözlenmektedir. Bu makale, modern tıp kütüphaneleri arasındaki dernekleşme boyutunu incelemektedir ve Türkiye'de kurulmuş olan tıp ve sağlık bilimleri kütüphane derneklerine de değinmektedir. Aynı bağlamda, ÜNAK Tıp ve Sağlık Bilimleri Çalışma Grubu'nun yaptığı çalışmalar da anlatılmaktadır.
\end{abstract}

Anahtar sözcükler: Tıp kütüphaneciliği, Kütüphanecilik dernekleriÜNAK, Çalışma Grupları

\begin{abstract}
Medical libraries play important roles in classifying, storing and providing access to medical information. Medical libraries are in steady development ever since 1850's. This study reviews the formation of associations among modern medical libraries, and also refers to the medical and health science library associations in Turkey. In that connection, a mention was also made to the work of the ÜNAK Medical and Health Sciences Working Group.
\end{abstract}

Keywords: Medical Libraries, Library associations-UNAK, Working Groups.

“ ÜNAK'06 "Bilimsel Iletişim ve Bilgi Yönetimi Sempozyumu, 12-14 Eylül 2006 Gazi Üniversitesi'nde sunulan bildirinin yeniden düzenlenmiş halidir.

Sağlık Bilimleri Kütüphanecisi, Koç Üniversitesi Hemşirelik Yüksekokulu Kütüphanesi (ggunes@ku.edu.tr). 


\section{Giriş}

Günümüzde en çok araştırma yapılan alan, insan sağlığının önemi nedeniyle tıp bilimidir. Yine aynı şekilde bu gelişmeye paralel en çok süreli yayın, tıp ve sağlık bilimleri alanında yayınlanmaktadır. Sağlık alanındaki bilgiler uygulamaya çok çabuk aktarıldığı için, bu alanın kütüphaneleri gelişime en açık olanlardır. Bu nedenle tıp ve sağlık bilimleri kütüphaneleri, gelişimlerine paralel olarak diğerlerine göre daha çabuk dernekleşme oluşumu göstermiştir.

Erwin H. Ackernect 1850'lerden itibaren gelişen tıbbı "Laboratuar Tıbbı" olarak adlandırır ve onu Ortaçağın kütüphane hekimliğinden, hasta başı tıbbından ve hastane hekimliğinden ayırmaya çalışır. Tıbbın 1850 'den sonraki ilerlemesi bilgi ve deneyim birikimlerinin yanı sıra büyük araştırıcı ve eğitimci hekimlerin yetişmesi, tıpta yeni disiplin dallarının gelişmeye başlaması, sanayileşmenin ortaya çıkardığı yaşama ve sağlık sorunları, yeni bilim dallarının gelişmesi ve tıp eğitimi veren birçok okulun açılmasında etken olmuştur (Unat, 1988, ss. 2-3). Belki yine diğer önemli etken de, bilginin daha kolay ve hızlı yayılımı ile farkı bir boyut kazanarak yayın sayısının ve araştırmaların artmasıdır. 19. yüzyılda yayınlanmaya başlayan ve bugün hala kütüphanelerde yer alan büyük ve önemli dergilerin ilk baskıları, hep bu tarih aralığına rastlamaktadır. Bu dergilere şunları örnek verebiliriz:

Acts Chirurgica Scandinavia (Nordiskt Mcxlicinskt Arkiv) 1869-

$>\quad$ Acts Medka Scandhavica (Nordiskt Medlcinskt Arkiv) 1869-

$>$ American Journal of Obstetrics and Gynecology 1868-

$>\quad$ American Journal $f$ of Ophthalmology 1884-

$>\quad$ American Journal of Psychiatry 1844-

$>\quad$ Annals of Surgery 1855-

$>\quad$ Archives of Dermatology 1882-

$>\quad$ Archives of Ophthalmology 1869-

$>\quad$ Brain 1878-

$>\quad$ British Dental Journal 1872-

$>\quad$ British Joumaf of Dermatology 1888-

$>\quad$ British Medical Journal 1857-

$>\quad$ Bulletin of the New York Academy of Medicine 1860-

$>\quad$ Chinese Medical Journal 1887-

$>\quad$ Deutsche Mediziniache Wochenschrift 1875-

$>\quad$ Eye 1880-

$>\quad$ JAMA (Journal of the American Medical Association) 1883-

$>\quad$ Journal de Pharmacie de Belgique 1845- 
$>\quad$ Journal de Physiologie 1868-

$>\quad$ Journal of Anatomy 1866-

$>\quad$ Journal of Bone and Joint Surgery-American Volume 1887-

$>\quad$ Journal of Cell Science 1852-

$>\quad$ Journaf of Laryngology and Otology 1887-

$>\quad$ Journal of Morphology 1887-

$>\quad$ Journal of Nervous and Mental Disease 1874-

$>\quad$ Journal of Pharmacy and Pharmacology 1870-

$>\quad$ Journal of Physiology 1878-

$>\quad$ Lancet 1820-

$>\quad$ Medical Journal of Australia 1856-

$>\quad$ Nature 1869-

$>\quad$ NEJM 1828-

$>\quad$ New York State Journal of Medicine 1884-

$>\quad$ New Zealand Medical Journal 1887-

$>\quad$ Pflugers Archiv-European Journal of Physiology 1868-

$>\quad$ Phamraceutisch Weekblad-Scientific 1864-

$>\quad$ Public Health Reports 1878-

$>\quad$ Revista Mechca de Chile 1872

$>\quad$ Schweizerische Medizinische Wochenschrift 1870-

$>\quad$ Science 1880-

$>\quad$ Union Medicale du Canada 1872-

$>\quad$ Virchows Archiv A \& B 1847-

$>\quad$ Wiener Medizinische Wohirenschrift 1851-

$>\quad$ Yakugaku Zaasbi-Joumal of the Pharmaceutical Society of Japan 1881-

$>\quad$ Zeitschrift fur Klinische Medizin-ZKM 1879-

> Zentralblatt fur Gynakologie 1877- (Garfield, 1987, ss. 166-169).

Bu dönemdeki Türkiye'de tıp eğitimi ve çalışmaları incelendiğinde, 14 Mart 1827 'de orduda görev yapacak hekimleri yetiştirmek için kurulan "Tıbhane-i Amire" ve 1867 yılında sivil tıp okulu "Mekteb-i Tıbbiye-i Mülkiye"de çağdaş tıp eğitimi verildiği görülmektedir (Hatemi, 2006, s. 68).

\section{İlk Gelişmeler ve Kuzey Amerika'da Tıp ve Sağlık Bilimleri Kütüphaneciliği}

\section{Amerikan Ulusal Tıp Kütüphanesi - National Library of Medicine (NLM)}

19. yüzyılda Amerika'da tıp eğitimi veren eğitim kurumlarının artması, başka oluşumları da beraberinde getirmiştir. Bu dönemde kurulan iki önemli kütüphanecilik oluşumu, modern tıp kütüphaneciliğinin 
temellerinin atılmasına da katkıda bulunmuştur. Dünyanın en büyük tıp kütüphanelerinden sayılan ve tıbbî literatürün toplanmasında ve yayılmasında yetkin olan Amerikan Ulusal Tıp Kütüphanesi (National Library of Medicine-NLM)'nin kuruluş tarihi 1818'dır. Halen Amerika Birleşik Devletleri hükümetince desteklenen bu kurumun koleksiyonunda, tıpla ilgili 7 milyondan fazla kitap, dergi, teknik rapor, nadir eser, mikrofilm, fotoğraf ve görüntü içermektedir.

1878 itibaren dergi yayın sayısının artışına paralel olarak Index Medicus'u yayınlamaya başlamıştır. Bugünkü sayısal değerlere bakıldığında 16 milyondan fazla makalenin künyesinin bu kütüphane üzerinden tüm dünyaya ulaştırıldığı görülmektedir.

\section{Amerikan Tıp Kütüphane Derneği - Medical Library Association (MLA)}

NLM'nin kuruluşu ile kütüphanelere ve kütüphanecilere verilen önem, o dönemde daha da artırmıştır. Tıp eğitimi veren üniversitelerin sayısındaki artış beraberinde tıp kütüphanelerinin ve kütüphanecilerinin sayısındaki artışı da getirmiştir. Tıp kütüphanecileri 1898'de bir araya gelerek ilk dernekleri olan Amerikan Tıp Kütüphane Derneği (Medical Library Association-MLA)'ni kurmuşlardır. Dünyanın en eski tıp kütüphanecileri derneği olarak dört kütüphaneci ve dört doktorun öncülüğünde oluşturulmuştur. Derneğin ilk başkanı Dr. George M. Gould (Bkz. Şekil 1), kurucu üyeleri ise William Osler ve Margaret Charlton'dır. (Bkz. Şekil 2) Başkan, doktor statüsünde bu dernekte yer alırken, diğer üç doktor da kütüphanelerinin temsilcileri olarak Derneğe katılmışlardır (Connor, 2002, ss. 8-12). Buradan bu yüzyılda doktorların kütüphaneleri yönettikleri çıkarımı yapılabilir.

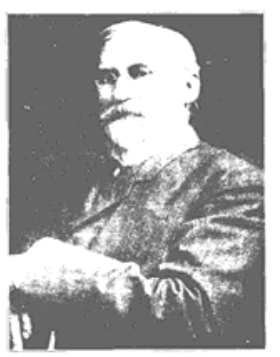

Şekil 1: (Kaynak: Connor, 2000, 41)

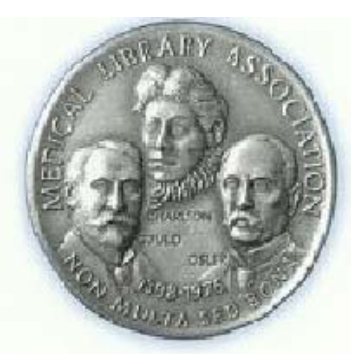

Şekil 2:(Kaynak: Connor, 2000, 11)2

Derneğin ilk kuruluş amacı; kütüphanecilere yönelik değil, o dönemde artan kütüphanelere yardım etmek, meslekte 
profesyonelleşmeyi sağlamak, ülke çapında bir toplu katalog oluşturmak, kütüphanelerden ve kütüphanecilerden istatistikî veriler toplamak olmuştur. Bu Derneğe Amerika'dan ve dünyadan 1200 kuruluş ve 3800'e kişi üyedir. Bölgesel olarak on dört alt kuruluşu, yirmi üç konusal alan bölümü ve on beş özel ilgi alan grubu olan Derneğin temel amaçları şunlardır:

> Tıp ve sağlık bilimleri kütüphaneciliğinde standartlaşma,

$>\quad$ Sağlık için kaliteli bilgi sağlamak ve sunmak,

> Gerekli profesyonel nitelikleri sağlamak,

> Sürekli mesleki eğitim destek sistemleri geliştirmek.

Tıp ve sağlık bilimleri kütüphaneciliğinin gelişiminde MLA'in kütüphaneciliğe ve kütüphanecilere katkısı, mesleğe yeni bir yön ve bakış açısı kazandırması bakımından diğer oluşumlardan farklıdır. Dernek, 1898 'ten beri yılda dört sayı olarak Journal of Medical Library Association (JMLA) adlı bir dergi ve yılda 10 sayı olarak MLA News isimli bir haber bülteni yayınlamaktadır. Ayrıca üyeleriyle iletişim ortamı yaratan bir haberleşme listesi ile http://www.mlanet.org adresinden erişilen bir web sitesi bulunmaktadır.

Türkiye'den Koç ve Marmara Üniversitesi bu derneğin üyesidir.

\section{Dünyada Tıp ve Sağlık Bilimleri Kütüphaneciliği}

II. Dünya Savaşı'ndan sonra bütün ülkelerdeki tıp kütüphanecilerin arasındaki koordinasyonun ve işbirliğinin sağlanması amacıyla, 1953 yılından itibaren IFLA ve Dünya Sağlık Örgütü (WHO) tarafından Uluslararası Sağlık Bilimi ve Kütüphanecileri Kongresi düzenlenmeye başlamıştır (Uşen, 2002, s. 93). Bu toplantı her 5 yılda bir farklı ülkelerde yapılmaktadır. Bu toplantının onuncusu 31 Ağustos - 4 Eylül 2009 tarihinde "Mesleğin Konumlandırılması" temasıyla Avustralya'da yapılacaktır.

1977 yılında IFLA'nın bir alt birimi olarak "Biyoloji ve Tıp Kütüphaneleri Bölümü” kurulmuştur. Bu grubun kurulmasında MLA'nin çalışmaların büyük etkisi olmuştur. Nina Matheson, Ruth Smith ve Irwin H. Pfzier öncülüğünde dokuz kurucu üye ile çalışmalarına başlayan grubun ilk başkanı, NLM'den Lois Ann Colaianni olmuştur. Bu bölüme kuruluş yıllarında dört kütüphanecilik derneği ile 11 kurum üye olarak görülmektedir. Bölümün amaçları kısaca şunlardır: 
$>\quad$ Kütüphaneler arası işbirliğinin güçlendirilmesi,

$>\quad$ Yeni teknolojiler ve uygulamalarla ilgili gelişmelerin kütüphaneler için kolaylaştırılması,

> U Ulusal ve uluslararası derneklerle, WHO ve diğer sağılı örgütleriyle işbirliğinin sağlanması,

> Sağlık ile ilgili bilgilerin öneminin vurgulanması ve sağlanması.

1980 yılında "World Directory of Biological and Medical Sciences Libraries" isimli rehber yayınlamışlardır (Law, 1990, s. 337). Bu bölümü ismi 2002 yılında Sağlık ve Biyobilimler Kütüphaneleri (Health and Biosciences Libraries) olarak değiştirilmiştir. Grubun 2001 yılından itibaren bir haber bülteni, üyeleriyle iletişim sağladığı bir haberleşme listesi ve her yıl IFLA toplantılarında kendi bölümleri için belirlemiş olduğu temalara işleyen düzenli yıllık toplantıları vardır.

$\mathrm{Bu}$ grubun desteklediği diğer önemli bir uluslararası toplantı ise, her beş yılda bir yapılan Uluslararası Sağlık Bilimi ve Kütüphanecileri Kongresi'dir. IFLA'nın bu bölümünün web adresi şöyledir: http://www.ifla.org/VII/s28/index.htm

\section{Avrupa'da Tıp ve Sağlık Bilimleri Kütüphaneciliği}

Avrupa Sağlık Bilimleri ve Kütüphaneleri Derneği - The European Association for Health Information and Libraries (EAHIL)

Avrupa'da tıp ve sağlık bilimlerinde dernek oluşumlarının daha sonra başladığı gözlenmektedir. Avrupa ülkelerindeki tıp ve sağlık bilimleri kütüphanecilerini bir araya getirmek amacıyla 26 kütüphaneci, 1985 yılında 5. Uluslararası Tıp Kütüphanecileri Kongresi sırasında bir dernek oluşturma isteklerini açıklamışlardır. 30 Eylül-5 Ekim 1986 tarihleri arasında Brüksel'de 300 tıp kütüphanecisinin katılımıyla ilk toplantılarını gerçekleştirmişler ve kapanış oturumunda The European Association for Health Information and Libraries (EAHIL) ismiyle derneğin kurulmasına karar vermişlerdir. Resmi olarak 18 Ağustos 1987 'de İngiltere'de çalışmalarına başlayan Derneğin 30 ülkeden 1140 üyesi bulunmaktadır. Üyeliğin ücretsiz olduğu Derneğe, Türkiye'den tıp ve sağlık bilimleriyle uğraşan 10 kütüphaneci derneğe üyedir. EAHIL Konseyinde Türkiye'den de bir temsilci bulunmaktadır. Derneğin web adresi: http://www.eahil.net

Avrupa ülkelerindeki kütüphaneciler, EAHIL'in dışında, bu alanda ulusal derneklerini de kurdukları gözlenmektedir (MLA Net, 2006). Bunlara örnek olarak şunlar verilebilir: 
$>$ The Nordic Association for Medical and Health Information (NAMHI)

$>\quad$ The Baltic Association for Medical Libraries (BAML)/ Baltijas Valstu Medicinas Biblioteku Asociacija

$>\quad$ The Danish Union of Librarians, Medical Subgroup /

Bibliotekarforbundet/Faggruppen for Medicinsk Information

$>\quad$ The Finnish Medical Library Association / Bibliothecarii Medicinae Fenniae ry Helsinki (BMF)

$>$ German Medical Library Association (GMLA)/Arbeitsgemeinschaft fur Medizinishces Bibliothekswesen (AGMB)

$>\quad$ Hungarian Medical Library Association/Magyar Orvosi Konyvtarak Szovettsege (MOKSZ)

$>\quad$ Icelandic Health Libraries Group/Samtarfshopur Laeknisfraedibokavarda

$>\quad$ Library Association of Ireland/Health Sciences Libraries Section (LAl/HSLS)

$>\quad$ The Association of Librarians and Documentalists of the National Health Service / Bibliotecari Documentalisti Sanita/Servizio Sanitario Nazionale (BDS/SSN)

$>\quad$ The Netherlands Association for Library, Information and Knowledge Professionals/Biomedical Information / Nederlandse Vereniging voor Beroepsbeoefenaren in de Bibliotheek-Informatieen kennissector/Biommedische Informatie (NVB/BMI)

$>\quad$ Norwegian Library Association/Section for Medicine and Health (NLA/SMH) / Norsk Bibliotekforening/Spesialgruppen for Medisin og Helsefag

$>$ Portuguese Association in Health Documentation and Information / Associacao Portuguesa de Documentacao e Informacao de Saude (APDIS)

> Sociedad Espanola de Documentacion e Informacion Cientifica (SEDIC) / Grupo de Bibliotecas de Ciencias de la Salud

$>\quad$ Swedish Library Association/Medical Subgroup / Svensk Bibliotekforening, Specialgruppen for Vardbibliotek

$>$ Schweizerische Akademie der Medizinischen Wissenschaften / Kommission der Biomedizinischen Bilbiotheken

$>$ Chartered Institute of Library and Information Professionals / Health Libraries Group (CILIP/HLG) 


\section{Asya ve Afrika'da Tıp ve Sağlık Bilimleri Kütüphaneciliği}

Japonya Tıp Kütüphane Derneği - The Japan Medical Library Association (NPO)

Japonya'da tıp kütüphaneciliği Avrupa'dan daha önce örgütlenmiştir. 1927 yılında Japon Hükümeti tarafından özellikle kütüphaneleri desteklemek amacıyla kurulan Japonya Tıp Kütüphane Derneği'nin, bugün toplam 229 üyesi bulunmaktadır. 1995 yılından itibaren sadece tıp kütüphaneleri değil, tıp kütüphanecilerinin de derneğe üye olmaları kabul edilmiştir. 2003 yılında yeni bir oluşuma gidilerek Derneğin ismi NPO The Japan Medical Library Association olarak değiştirilmiştir (Masaaki, 2005). Dernek, yılda dört sayı olarak Igaku Toshokan isimli bir dergi yayınlamaktadır.

Afrika Sağlık Bilimi ve Kütüphaneleri Derneği -The Association for Health Information and Libraries in Africa (AHILA)

Afrika kıtasındaki tıp ve sağlık biliminin ve kütüphanelerinin mesleki ve profesyonel anlamda desteklenmesi amacıyla, 1984 yılında kurulan Afrika Sağlık Bilimi ve Kütüphaneleri Derneği'nin Afrika'dan ve dünyadan toplam 46 üyesi bulunmaktadır.

\section{Avustralya ve Güney Amerika'da Tıp ve Sağlık Bilimleri Kütüphaneciliği}

ALIA/HLA (ALIA Sağlık Kütüphaneleri Bölümü)

Avustralya Kütüphane ve Bilgi Derneği (Australian Library and Information Association - ALIA)'nin yapısı altında ALIA Sağlık Kütüphaneleri Bölümü (ALIA/HLA) oluşturulmuştur. Bu grup, Avustralya'daki tıp ve sağlık bilimcilerinin mesleki gelişimi, iletişimi ve işbirliğini geliştirmek ve araştırmaları desteklemek amacıyla kurulmuştur.

Arjantin Biyotıp Kütüphaneleri Derneği - Asociación de Bibliotecas Biomédicas Argentinas (ABBA)

Arjantin Biyotıp Kütüphaneleri Derneği, Arjantin'deki biyotıp kütüphaneleri ile dünyada İspanyolca konuşan tıp kütüphanecilerini desteklemek amacıyla 15 Mart 1999'da kurulmuştur. Bu derneğe 170 kütüphane ile 183 kütüphaneci üyedir. Daha önce Arjantinli tıp kütüphanecilerin kurmuş olduğu haberleşme listesi BIBLIOMED, halen Derneğin haberleşme listesi olarak sürdürülmektedir. Ülke çapında oluşturdukları bir toplu katalog çalışmaları vardır. 
PROFICSA(Asociación de Profesionales de la Información en Ciencias de la Salud)-Sağıık Bilimleri ve Bilimcileri Profesyonelleri Derneği

Meksikalı sağlık ve tıp bilimcilerini desteklemek amacıyla 2000 yılında kurulmuştur.

\section{Türkiye'de Tıp ve Sağlık Bilimleri Kütüphaneciliğg}

ÜNAK - Tıp Ve Sağlık Bilimleri Çalışma Grubu

1987 yılında ÜNAK altında tıp kütüphanecilerinin bir araya gelerek işbirliği içinde çeşitli çalışmalar yapması fikri ortaya atılmıştır. Ancak 2000 yılında "INET-TR 2000" toplantısında tıp kütüphanecileri INET-TR Tıp Çalışma Grubu altında iki toplantı yapmışlar ve çeşitli kararlar almışlardır. Bu oluşum, 2000 yılında ÜNAK'a bağlı olarak "Tıp ve Sağlık Bilimleri Çalışma Grubu" Aytaç Yıldızeli'nin başkanlığında gerçekleşmiştir. Grubun kuruluş amacı özetle şöyledir:

$>$ Tıp enformasyonunun gelişimine katkıda bulunup dünya standartlarını yakalayabilmek,

$>$ Tıp enformasyonu ile ilgili bir el kitabının çıkarılmasını desteklemek,

> Türkiye'de toplantılar seminerler yaparak, ayrıca Türk tıp kütüphaneciliğinin ilerlemesine katkıda bulunmak,

$>\quad$ Tıp terimlerinin Türkçeleştirilerek standartlaştırılmasını sağlamak,

$>\quad$ Tıp ve sağlık bilimleri ilgili yayın yapmak ve yapılan yayınları desteklemek,

> Sağlık bilimleri çalışanlarıyla ortaklaşa projeler üretmek.

Grup, 2002 yılında 19-20 Eylül 2002'de İstanbul'da Koç Üniversitesi'nde yapılan Ulusal Tıbbî Bilgi Yönetimi ve Teknolojileri Sempozyumu'nu gerçekleştirmiştir. Sempozyumun amacı bilgiye erişim hizmetleri sunan tıp kütüphanecileri ile bilginin basılı ve elektronik ortamda sunulmasını sağlayan bilgi sağlayıcılarının, dergi editörlerinin ve hem bilgi üretici, hem de kullanıcısı olan sağlık profesyonellerinin bir araya gelmesini sağlamak ve disiplinler arası iletişimin gerçekleşmesine katkıda bulunmaktır. Sempozyuma kütüphaneci, tıp doktoru, sağlık/tıp ağırlıklı dergi editörleri ve yayıncılar olmak üzere toplam 97 kişi katılmıştır. İki gün süren ve ilgiyle izlenen Sempozyumda, panel sayısının fazla olması büyük tartışma ortamının yaratılmasına olanak sağlamıştır. 
İkinci toplantı ÜNAK'03 ve II. Ulusal Tıbbî Bilgi Yönetimi ve Teknolojileri Sempozyumu olarak ÜNAK Yıllık Toplantısı ile beraber 2527 Eylül 2003 tarihleri arasında Ankara'da Başkent Üniversitesi'nde yapılmıştır. Üçüncü toplantı ÜNAK'04 ve III. Ulusal Tıbbî Bilgi Yönetimi ve Teknolojileri Sempozyumu olarak ÜNAK Yıllık Toplantısı ile birlikte 22-25 Eylül 2004 İstanbul'da Maltepe Üniversitesi'nde yapılmıştır.

Grup üyelerinin iletişimi için 2006 yılında UNAK-TIP isimli bir haberleşme listesi oluşturulmuştur. 2007 yılı itibarıyla listede Türkiye'den ve dünyadan 35 üye bulunmaktadır. 2006 yılında Güssün Güneş başkanlığında grup çalışmalarına devam etmektedir.

ÜNAK Tıp ve Sağlık Bilimleri Çalışma Grubu 2006-2010 Yılı Projeleri şöyle özetlenebilir.

1- ÜNAK Tıp Grubu haberleşme listesinin aktif hale getirilerek üye sayısının artırılması,

2- Grubun web sayfasının hazırlanması,

3- Tıbbî Bilgi Yönetimi ve Teknolojileri Sempozyumu'nun ÜNAK yıllık toplantılarından bağımsız olarak yapılması ve sempozyum ile ilgili bütçenin ve desteğin yeniden yapılandırılması ve tıp ve sağlık bilimleri alanında geniş bir katılımın sağlanması,

4- Avrupa Sağlık Bilimleri ve Kütüphaneleri Derneği (EAHIL)'e ÜNAK Tıp Grubu'nun üye olması ve yıllık toplantılara gruptan katılım sağlanması, gelecek beş yıl içinde bu önemli toplantının ÜNAK tarafından Türkiye'de yapılması için Derneğe çağrı yapılması. EAHIL'a ülkemizden daha çok kütüphanecinin üye olması,

5- Grup tarafından tıp ve sağlık bilimleri kütüphanecilerine ve çalışanlarına yönelik hizmet içi eğitim programlarının planlanması ve eğitim verilmesi,

6- Bilgi ve Belge Yönetimi Bölümlerinde tıp ve sağlık bilimleri kütüphaneciliği hakkında derslerinin programa eklenmesi,

7- İletişim amacıyla ülkemizdeki tıp kütüphanecilerinin tam bir rehberinin oluşturularak Tıp ve Sağlık Bilimleri Çalışma Grubu'nun web sayfasına konulması,

8- Türkiye'de yayınlanan dergilerin kısaltmalarının standartlarının oluşturulması, Çalışmanın proje haline getirilerek ULAKBIM'e ya da TÜBiTAK'a sunulması,

9- Türkiye Tıp ve Sağlık Bilimleri Dergi Rehberi'nin tamamlanarak basımı yapılmış ve isteyen kütüphanelere dağıtımına başlanmıştır. 
10- MeSH başıklarının Türkçeye çevirerek NLM'de yer alınmasının sağlanması amacıyla bir proje hazırlanması planlanmaktadır.

\section{Tıp Bilişimi Derneği}

Dernek, 1999 yılında Ankara'da, bir grup hekim ve bilişim profesyoneli tarafından kurulmuştur. Derneğin kuruluş amaçları arasında "sağlık bilişimi ve tıp bilişimi ile ilgili tüm profesyonellerin çağdaş bilgi ve beceri düzeyine ulaşmasını teşvik etmek, profesyonellerin iletişimi ve bilgi paylaşımı için zemin hazırlamak, çok disiplinli çalışmaları teşvik etmek" de bulunmaktadır (Tıp Bilişimi Derneği, t.y.). Bu kapsamda Türkiye'de tıp ve sağlık bilimleri kütüphaneciliğinin gelişmesinde Derneğin önemli katkıları olacağı düşünülmektedir.

\section{Sonuç ve Öneriler}

Sağlık bilimlerindeki hızı gelişim, dernekleşmenin de önemini artırmıştır. Türkiye'de henüz tıp bilişimi ile ilgili eğitim ve çalışmalar yeterli düzeyde değildir. Halen tıp fakülteleri olan üniversiteler ve hastanelerdeki kütüphanelerde, klasik bilgi hizmetleri verilmeye devam etmektedir.

Dünyadaki bilgibilim ve bilgi hizmetleri eğilimleri doğrultusunda, tıp kütüphanecilerinin örgütlenmesi, bilgilenmesi ve bu mesleği gelişmiş ülkelerdeki gibi yapılabilmesinin sağlanması için çalışmaların artması gerekmektedir. Ayrıca Bilgi-Belge Yönetimi Bölümlerinde tıp bilişimi ile ilgili derslerle uzmanlık programların geliştirilmesi, lisansüstü çalışmalarında tıp fakülteleriyle işbirliği yapılması, yeni bilgilerle donanmış tıp kütüphanecilerinin yetişmesini sağlayacaktır. Böylece sağlık bilimleri gibi hızı gelişen bir alanda çalışan araştırmacılara daha kaliteli bilgi hizmetlerinin ulaşması mümkün olacaktır.

\section{Kaynakça}

ABBA. (2004). BIBLIOMED La Red de Bibliotecas Biomédicas Argentinas. 15 Ekim 2006 tarihinde http://www.sai.com.ar/abba erişildi.

AHILA. (t.y). The Association for Health Information and Libraries in Africa. 12 Ekim 2006 tarihinde http://www.ahila.org adresinden erişildi.

ANKOS. (t.y). Veri tabanı denemeleri. 10 Ekim 2005 tarihinde ANKOS web sitesinden erişildi: http://www.ankos.gen.tr/

Connor, J. (2000). Guardians of medical knowledge: the genesis of the Medical Library Association. Chicago: Medical Library Association.

EAHIL. (2002). General information. 8 Ekim 2006 tarihinde http://www.eahil.net/general_information.htm adresinden erişildi. 
Garfield, E. (1987). The 170 Surviving Journals That CC Would Have Covered 100 Years Ago. Essays of an Information Scientist, 10, 164-173.

Hatemi, H. (2006). Türk tıp eğitiminin önemli adımları. İstanbul: CSA Global Publishing.

IFLA. (2006). Health and Biosciences Libraries Section. 10 Ekim 2006 tarihinde http://www.ifla.org/VII/s28/index.htm adresinden erişildi.

Law D. G. (1990). The international scene in biological and medical libraries. Bulletin of the Medical Library Association, Oct; 78(4), 337-338.

Masaaki,T. (2005). informatio medicata 2005: The healing information. 10 Ekim 2006 tarihinde http://www.lib.sote.hu/files/moksz/2005/ support_researchers.ppt adresinden erişildi.

MLA Net. (2006) Allied Groups and Other Resources. 10 Ekim 2006 tarihinde http://www.mlanet.org/resources/allied_lnks.html adresinden erişildi.

MLA. (2006). 5 Ekim 2006 tarihinde MLA Web sitesinden erişildi: http://www.mlanet.org

NLM. (t.y). 5 Ekim 2006 tarihinde National Library of Medicine Web sitesinden erişildi: http://www.nlm.nih.gov

Tıp Bilişimi Derneği. (t.y). Amaç. 26 Mayıs 2007 tarihinde http://www.turkmia.org/amac.php adresinden erişildi.

Unat, E. K. (1988). Dünya'da ve Türkiye'de 1850 yılından sonra tıp dallarındaki ilerlemelerin tarihi. İstanbul: Cerrahpaşa Tıp Fakültesi Vakfı Yayınları.

Uşen, S. (2002). Yirmibirinci yüzyılda tıp kütüphanecilerinin değişen rolleri. Bilgi Dünyası, 3(1), 93-99. 